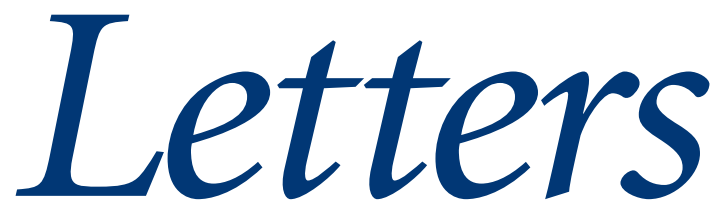

All letters are subject to editing and may be shortened. Letters should be sent to the BJGP office by e-mail in the first instance, addressed to

journal@rcgp.org.uk (please include your postal address). Alternatively, they may be sent by post as an MS Word or plain text version on CD or DVD. We regret that we cannot notify authors regarding publication. Letters not published in the Journal may be posted online on our Discussion Forum. For instructions please visit: http://www.rcgp.org.uk/bjgp-discuss

\section{Diagnostic safety-netting}

Congratulations on your article that is very helpful for developing countries. ${ }^{1}$ As you have mentioned, undifferentiated presentations and uncertainty in management are an important issue to GPs. I wish to include three clear situations:

- You may see the obvious 'redflag' that you will not miss or take a chance with. A middle-age female who presents with sudden onset, severe headache that she has not experienced before and no physical signs detected. This may be a subarachnoid hemorrhage even though you cannot exclude a first attack of migraine. Do not take any chances, play it safe.

- May expect a 'redflag' later. The article' mentioned that in some situations the time period is certain; for example, head injury leading to subdural hematoma. I do not agree as the safety-netting period may depend on so many factors. Site of injury, severity of injury, and age. Another classic example: a patient with heartburn has a normal ECG suggestive of gastroesophageal reflux disease. As you are aware $50 \%$ of ECGs in the first 6 hours could be normal. You may repeat after 6 hours and may rule out an infarct. I have seen a frank Ml showing in the ECG even after 24-48 hours.

- A patient who has typical features suggestive of IBS has a diagnosis card indicating the same. The same patient is diagnosed with colonic carcinoma after 6 months. Have you misdiagnosed or have they developed a colonic carcinoma later?

These are questions we have to answer in general practice.
Anthony Seneviratne,

54/10 Chakkindarama Road, Ratmalana,

Sri Lanka. E-mail: alprs@eureka.lk

\section{REFERENCE}

1. Almond S, Mant D, Thompson M. Diagnostic safetynetting. Br J Gen Pract 2009; 56(568): 872-874.

DOI: 10.3399/bjgp10X483986

\section{Looking at the patient}

I wish to comment on the editorial in the February 2010 issue of the Journal. ${ }^{1}$ My personal experience of analysing my consultations by video made it clear to me that the computer served as a very real barrier to effective non-verbal communication with patients. I noted that the position of the computer on my desk was of considerable importance. As the authors describe, the position of the lower body identified by Ruusuvuori is crucial and as such, I found that angling the computer keyboard and monitor toward the patient without blocking my direct view, seemed to integrate the computer into the interaction with the patient much more effectively. This is a very simple reorganisation but interestingly I noted that in all of the eleven consulting rooms in our building, we were operating with a keyboard and screen placed at angle of 45-90 degrees away from the patient.

I agree entirely with the need to give full attention to the patient's opening statements before using the computer and also in signposting any referral to the screen. However, I have also been increasingly aware of the challenge of recording a full computerised record within the time constraints of a 10-minute consultation. I have been experimenting with entering data on the computer without breaking eye contact with the patient. This requires typing skills, however, I have managed to pick these up having previously used the ubiquitous two-to-four finger typing technique over a relatively short period of 6 months or so and now consider it to have been a useful investment of time. This technique needs structuring with some explanation to the patient and seems to be best carried out during free flowing conversation in the consultation. However, it allows data to be entered unobtrusively and contemporaneously while still being able to engage in the offer and receipt of non-verbal information.

\section{Graeme I Hay,}

Alva Health Centre, West Johnstone Street, Clackmannanshire.

E-mail: graeme.hay716@btinternet.com

\section{REFERENCES}

1. Silverman J, Kinnersley P. Doctors' non-verbal behaviou in consultations: look at the patient before you look at the computer. Br J Gen Pract 2010; 60(571): 76-78.

2. Ruusuvuori J. Looking means listening: coordinating displays of engagement in doctor-patient interaction. Soc Sci Med 2001; 52(7): 1093-1108.

DOI: 10.3399/bjgp10X483995

\section{Persistent frequent attenders}

We read with great interest the article by Luciano et al about frequent attendance in the BJGP.'

The authors state that 'neither definition (has taken) into account that certain patients need to make more consultations than others,' and therefore, they study a twostage approach in that they define frequent attenders according to four clinical profiles and to the top 25 and $10 \%$ top attenders.

Obviously sick patients will make more appointments with their GP and frequent attendance is linked to (multi-)morbidity. Therefore, we think that, from a clinical 
perspective of a GP, thinking in strict profiles of frequent attenders denies the complexity of consulting behaviour. Our research group prefers to analyse frequent attendance as a clinical risk phenomenon: consulting exceptionally more than your peers may be a sign for GPs that a mismatch exists between the needs of these patients and the actual care delivered by the GP; a sign that there are undiscovered and unmet (medical) problems. In this perspective it makes sense to only select the top attenders stratified by age and sex (method 2 in this article).

Taking a certain number of consultations as a criterion will result in a selection of relatively many older women and diminishes the number of exceptional consulters among the young. ${ }^{2}$ Selecting $25 \%$ of your practice is too much to be of any practical usefulness in this concept. Therefore, we think that defining frequent attenders as a (10\%) proportional part of all enlisted patients is the best method to select the exceptional attenders in all age and sex categories. Also, this method makes it possible to compare between countries and different practices. ${ }^{2,3}$

Most 1-year frequent attenders have good reasons to consult more often because of intercurrent disease or other (medical, social, or psychological) problems. Therefore, most frequent attendance is temporary. Only a minority persist in frequent attendance. ${ }^{4}$ Moreover, persistent frequent attenders have more (multi-) morbidity, compared with 1-year frequent attenders, and their consulting behaviour is, by definition, not determined only by intercurrent illnesses. ${ }^{4}$

Therefore, we stated in a paper in this Journal that for GPs persistent frequent attending is of more importance and clinical usefulness than short-term frequent attending. ${ }^{5}$

Unfortunately, the authors did not raise this issue in their paper.

\section{Frans Smits,}

Department of General Practice, Academic Medical Centre, University of Amsterdam, Meibergdreef 15, 1105AZ Amsterdam,

The Netherlands.

E-mail: f.t.m.smits@chello.nl

\section{Henk Brouwer,}

Department of General Practice, University of Amsterdam.
Gerben ter Riet,

Department of General Practice, University of Amsterdam.

\section{REFERENCES}

1. Luciano JV, Fernandez A, Pinto-Meza A, et al. Frequent attendance in primary care: comparison and implications of different definitions. Br J Gen Pract 2010; 60(571): 95-100.

2. Smits FT, Mohrs JJ, Beem EE, et al. Defining frequent attendance in general practice. BMC Fam Pract 2008; 9: 21

3. Vedsted P, Christensen MB. Frequent attenders in general practice care: a literature review with special reference to methodological considerations. Public Health 2005; 119(2): 118-137.

4. Smits FT, Brouwer HJ, Ter RG, van Weert HH. Epidemiology of frequent attenders: a 3-year historic cohort study comparing attendance, morbidity and prescriptions of one-year and persistent frequent attenders. BMC Public Health 2009; 9: 36.

5. Smits FTM, Brouwer HJ, ter Riet G, van Weert HC Predictability of persistent frequent attendance. A historic 3-year cohort study. Br J Gen Pract 2009; 59(59): e44-50.

DOI: 10.3399/bjgp10X484002

\section{Frequent attendance from different points of view}

Frequent attenders' (FAs') phenomenon is one of the major discouraging problems that GPs have to face in their everyday life. As Luciano et al write, ${ }^{1}$ this proportion of patients generates a great cost for public health systems and considerable workload and frustration for GPs.

However, the institutions seem not to be concerned about the problem, and GPs are left alone to deal with it. Many studies have tried to trace a stereotype of the FAs, showing a high incidence of psychiatric illness and social problems. Luciano et al's article indicates these factors as systematically related to this status and the main reasons for consulting as: being on sick leave, being born outside of the country, and reporting mental health problems.

In Italy, we tried to find out other characteristics of the FAs that could help GPs solve the problem. ${ }^{2,3}$

These characteristics were examined: number of GP consultations, age, sex, social problems, trust in the doctors, and influence of the mass media. Patients with major diseases that appropriately required a high rate of consultations were excluded.

These characteristics were prominent: lack of trust in the other doctors, influence of the mass media, and conflictual relationships with their disease.

The FA's problem is not only a social and psychiatric matter. Often the misuse and abuse of healthcare system is deliberate. The attitude and the structural bureaucracy of the healthcare system towards the patient very often facilitates the occurrence of FAs' phenomenon.

I think that these differences in results are important and indicate a need for more research of the topic. We need a clear definition of 'frequent attendance' that would separate clinical from administrative, psychological, environmental, and misuse aspects. I agree with the authors that a health care system's policy change is required. Also, a number of GPs think that a ticket paid by every patient for consultations, home visits, and other procedures might increase the patient sense of moderation and reduce their attendance without a clinical reason, the way it is for specialistic consultations.

\section{Francesco Carelli,} GP Professor, University of Milan, EURACT Council Director of Communications. E-mail: carfra@tin.it

\section{REFERENCES}

1. Luciano JV, Fernández A, Pinto-Meza A, et al. Frequent attendance in primary care: comparison and implications of different definitions. Br J Gen Pract 2010; 60(571): 95-100.

2. Petrazzuoli F, D'Addio F, Carelli F, et al. Frequent attender phenomenon: the health care system achilles' heel and (moreover) the general practitioner's everyday life hell. Oral presentation at the 2002 Conference of the European Society of General Practice/Family Medicine Wonca Region Europe. London: Queen Elizabeth Conference Centre, 9-13 June 2002.

3. D'Addio F, Petrazzuoli F, Carelli F, et al. Frequent attender phenomenon: when the patients challenge the GP to more professionalism, to more flexible management of their health, or their diseases. Oral presentation at the 2002 Conference of the European Society of General Practice/Family Medicine Wonca Region Europe. London: Queen Elizabeth Conference Centre, 9-13 June 2002.

DOI: 10.3399/bjgp10X484011 